\title{
Influência do gasto público no fortalecimento da centralidade de Pau dos Ferros/RN
}

\author{
Influence of public spending on the strengthening \\ of the centrality of Pau dos Ferros/state of Rio Grande do Norte
}

Ronie Cleber de Souza [I] Humberto Miranda [II]

\begin{abstract}
Resumo
As novas centralidades passaram a ter um papel mais destacado na malha urbana brasileira desde a década de 2000. A cidade de Pau dos Ferros, localizada no estado do Rio Grande do Norte, destacou-se ao expandir sua influência regional no período 2003-2014. 0 objetivo deste texto é entender como o gasto público fortaleceu a centralidade regional dessa cidade. A hipótese discutida é de que o gasto público é um elemento fundamental para garantir a integração urbano-regional de cidades intermediárias localizadas nas áreas não metropolitanas do Nordeste brasileiro. Conclui-se que, dentre os gastos públicos, aqueles direcionados ao ensino superior foram decisivos para que 0 município de Pau dos Ferros atingisse maior relevância regional.
\end{abstract}

Palavras-chave: gasto público; integração urbano-regional; educação superior; cidade intermediária; Pau dos Ferros-RN.

\begin{abstract}
The new centralities started to play a more prominent role in the Brazilian urban network in the 2000s. The city of Pau dos Ferros, located in the state of Rio Grande do Norte, stood out by expanding its regional influence between 2003 and 2014. The purpose of this text is to understand how public spending has strengthened the regional centrality of Pau dos Ferros. The hypothesis discussed here is that public spending is a fundamental element to guarantee the urban-regional integration of intermediate cities located in the non-metropolitan areas of Northeastern Brazil. The conclusion is that, among public expenditures, those directed to higher education were decisive for the municipality of Pau dos Ferros to achieve greater regional relevance.
\end{abstract}

Keywords: public spending; urban-regional integration; higher education; intermediate city; Pau dos Ferros-Rio Grande do Norte. 


\section{Introdução}

As discussões sobre o gasto público no Brasil têm se concentrado quase que exclusivamente em critérios de ajuste fiscal das contas públicas, por meio da diminuição dos gastos correntes, dos repasses a estados e municípios e dos investimentos públicos. Por conta disso, tem prevalecido uma visão de curto prazo cuja ênfase são os critérios de austeridade financeira como condição inevitável à retomada do crescimento econômico. Diante de um ciclo econômico expansivo ou recessivo, seja para enfrentar um cenário de crescimento persistente dos preços internos, seja para lidar com uma crise financeira de origem externa ou para reagir a uma queda contínua na arrecadação de impostos, não importa, a premissa é sempre a mesma: corte de gastos públicos.

Essa típica medida de política neoliberal fez com que a perspectiva de longo prazo da economia ficasse em segundo plano, condicionando o pouco que há de planejamento público a "sobras de caixa". Essa situação tem produzido efeitos deletérios quanto à contratação e/ou à execução de investimentos públicos e privados para atender a demandas sociais e econômico-setoriais vitais ao País. Ademais, as transferências constitucionais obrigatórias para regiões e municípios de áreas não metropolitanas, principalmente quando a intenção é fortalecer o equilíbrio federativo por meio do aporte de recursos em cidades pequenas e médias de determinados contextos regionais (Dantas, Clementino e França, 2015; Gomes Júnior, 2015; Porto, 2016), ficam sujeitas a cortes frequentes ou contingenciamentos orçamentários prolongados.
Após 30 anos de vigência da Constituição Federal de 1988 (CF88), as mudanças, para pior, que se processaram na execução do gasto público, em boa medida, decorreram das políticas macroeconômicas adotadas, produzindo maiores ou menores restrições. Tal não foi a surpresa quando o novo ciclo de investimentos públicos, inaugurado nos anos 2000, chegou e gerou impactos positivos na estrutura e na execução dos gastos em geral, ao menos até 2015. De acordo com Orair (2016b, p. 12), o desempenho do novo ciclo de gasto público passou por três fases distintas: foi declinante no período 1999-2005, após a entrada em vigor da Lei de Responsabilidade Fiscal, em 4 de maio de 2000; estava em franca recuperação no subperíodo 2006-2010, com a retomada dos investimentos; ${ }^{1}$ e interrompeu a recuperação no subperíodo 2011-2014, devido à recessão decorrente do forte ajuste fiscal de 2015.

Independentemente do quadro recessivo que se apresentou, o autor argumenta que o problema central estava na "rigidez da política fiscal" e na fragilidade dos mecanismos usados dentro do regime fiscal em vigor para "flexibilizar os entraves orçamentários aos investimentos". Segundo Orair (ibid.), nem mesmo as transferências intergovernamentais amenizaram a situação fiscal, porque elas são sensíveis ao ciclo econômico (crescimento/ recessão), acarretando certa volatilidade às receitas públicas e obrigando os entes subnacionais a recorrerem ao endividamento, o que acaba reforçando o ajuste fiscal também endogenamente. Essa situação gerou maior dependência por parte dos estados e municípios em relação aos recursos da União, para cobrirem despesas e realizarem investimentos. 
Nesse sentido, o papel da União foi especialmente importante no período 20032014, quando houve ampliação da rede da proteção social, projetando o aumento continuado da demanda por políticas urbanas (infraestrutura e moradia) e por serviços sociais básicos nos estados e municípios (saúde e educação). Convém destacar o crescimento da arrecadação própria dos municípios brasileiros, de $1,7 \%$ para $2,3 \%$ do Produto Interno Bruto (PIB) do País entre 2002 e 2014 (Orair, 2016a). De forma complementar, o pacto federativo desenhado pela CF88, criando uma estrutura de gastos sociais obrigatórios (educação, saúde, saneamento), permitiu um nível mínimo de autonomia financeira aos municípios e estabeleceu novos marcos institucionais e territoriais para a gestão pública via a aprovação da Lei dos Consórcios Públicos, lei n. 11.107 (6 de abril de 2005).

Dado o contexto mais geral, cabe salientar que o conceito de gasto público aqui adotado é o constitucional, sendo por isso mais abrangente, ou seja, é a despesa mais o investimento. Assim, diante de um cenário macroeconômico conservador, marcado pela aversão ao crescimento do gasto público, regiões mais pobres, como o Nordeste, acabariam sofrendo impactos negativos. Essa afirmação, entretanto, não é de todo correta quando são apresentadas evidências de que a queda da desigualdade e o crescimento da economia das pequenas e médias cidades ocorrem desde a universalização do acesso aos benefícios previdenciários ${ }^{2}$ estabelecida pela CF88 e pela execução de políticas e programas sociais pós-2006.

Metodologicamente, cabe reconhecer que há dificuldades para tratar separadamente os efeitos dos gastos constitucionais obrigatórios daqueles que têm a ver com a execução de políticas, planos e programas para municípios de pequenos e médio portes. No fundo, esses gastos têm grande complementaridade entre si. Uma escola que é mantida pelo fundo público e que não conta com uma estrada adequada e acessível aos estudantes, por exemplo, terá negativamente afetado o seu compromisso com a educação (objetivo principal do gasto). Por isso, optou-se, neste texto, pelo conceito abrangente (constitucional) de gasto público, destacando aqueles ou aquele com maior resultado para o fortalecimento do papel regional do município de Pau dos Ferros-RN.

Concernente aos investimentos, os que foram executados no âmbito do Programa de Aceleração do Crescimento (PAC), no subperíodo 2006-2010, e o avanço de algumas políticas públicas (interiorização do ensino superior, Programa Luz para Todos, valorização real do salário-mínimo, entre outras) tiveram efeitos importantes na dinâmica econômica e urbana das cidades de porte médio e pequeno em regiões como o Nordeste. ${ }^{3}$ Em suma, nesse período, essas cidades se tornaram polos relevantes para o provimento de serviços públicos, especialmente em áreas não metropolitanas ou mais distantes das capitais de estado, apesar dos condicionantes macroeconômicos supracitados.

Pode-se afirmar, portanto, que os diagnósticos sobre os impactos positivos da CF88 no que se refere aos gastos obrigatórios estão são bem cobertos pela literatura especializada, mas o impacto do conjunto dos gastos públicos na economia de cidades nordestinas, via transferências ou investimentos e, sobretudo, por meio do robustecimento das políticas e programas sociais no período 2003-2014, ainda não foi suficientemente tratado no que respeita aos seus efeitos urbano-regionais. 
Pergunta-se: em que medida o fortalecimento do papel regional da cidade de Pau dos Ferros, situada no interior do estado do Rio Grande do Norte (RN), decorreu da crescente importância do gasto público na provisão de bens e serviços no período 2003-2014?

A hipótese trabalhada é de que, a exemplo de muitas outras cidades importantes na estruturação da rede urbana nordestina, Pau dos Ferros aumentou sua centralidade, ganhando status de cidade intermediária, devido à importância redistributiva dos gastos públicos na região do Alto Oeste Potiguar, sendo a provisão de educação superior um dos elementos explicativos fundamentais de sua maior integração urbano-regional.

Portanto, o objetivo deste texto é entender o papel do gasto público no fortalecimento da centralidade regional de Pau dos Ferros, favorecendo tanto o seu ganho de status como cidade intermediária, como a integração urbano-regional do Rio Grande do Norte, na região Nordeste do Brasil.

0 texto é composto, além desta introdução, de mais três seções e as considerações finais. Na próxima seção, discorre-se sobre Pau dos Ferros e seu contexto regional; a seguinte trata da influência do papel do Estado, ao longo do tempo e atualmente, na centralidade regional de Pau dos Ferros; e a terceira discute a importância decisiva do ensino superior no fortalecimento da centralidade regional de Pau dos Ferros atualmente. Logo após, são feitas as considerações finais.

\section{0 crescimento} socioeconômico na região do Alto Oeste Potiguar e o papel de Pau dos Ferros

Esta seção tem por objetivo discorrer sobre a cidade de Pau dos Ferros, sua região imediata e situação regional, a fim de destacar alguns fatores que a diferenciam regionalmente e ajudam a entender as condições gerais de integração urbano-regional.

O município de Pau dos Ferros está localizado em pleno semiárido nordestino e à distância de 400 km da capital do Rio Grande do Norte, Natal. Está encravado em uma região de fronteira com os estados do Ceará e de Paraíba, possuindo 27.745 habitantes em 2010 e apresentando-se como um município majoritariamente urbano, cujo grau de urbanização é de $92,09 \%$, segundo o IBGE. Na divisão regional do estado, o município situa-se na região do Oeste Potiguar, também conhecida como "Alto Oeste Potiguar", conforme a Figura 1.

A localização geográfica de Pau dos Ferros é privilegiada, sendo entrecortada por duas estradas federais (BRs 405 e 226) e uma estadual (RN 177) que se conectam com as pequenas cidades do entorno e os grandes centros urbanos regionais. Dentre os poucos núcleos urbanos que têm se destacado na hierarquia urbana do Rio Grande do Norte, Pau dos Ferros é classificado como centro sub-regional nível $\mathrm{B}$, conforme a atual classificação do Regic 
Figura 1 - Divisão Regional do estado do Rio Grande do Norte

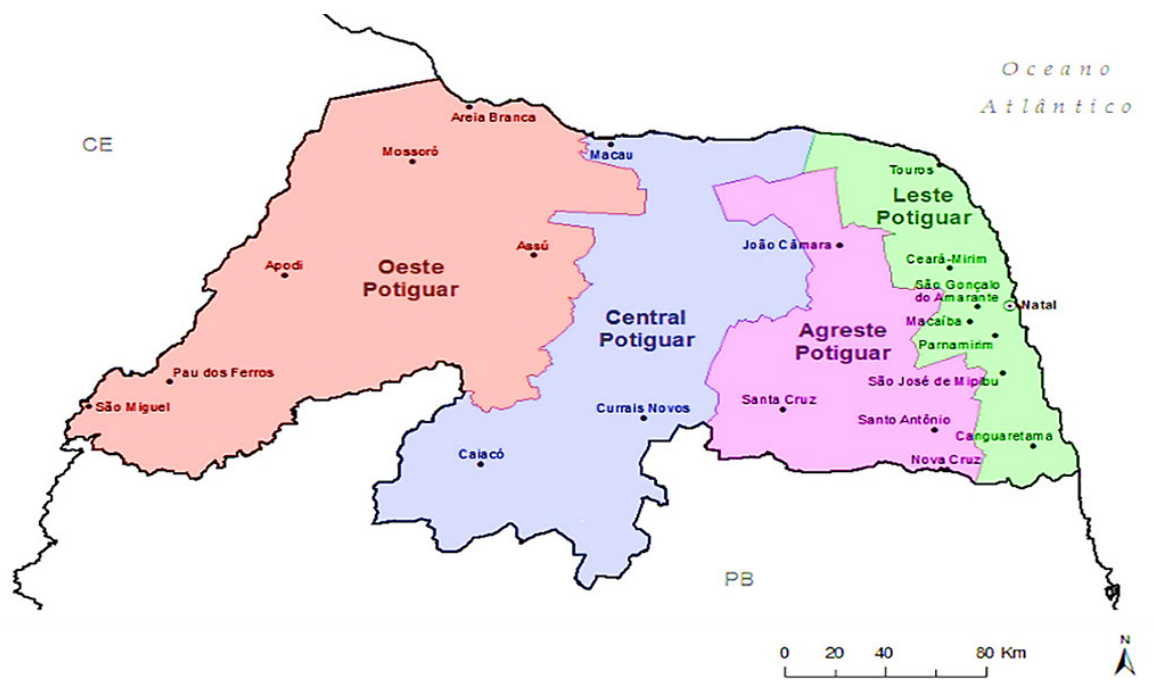

Fonte: Lucena, Cabral Júnior e Steinke (2018). Pau dos Ferros em destaque.

(IBGE, 2018). Depois de Mossoró (centro regional C), Pau dos Ferros junta-se a Açu (RN), Caicó (RN) e Currais Novos (RN) como centro sub-regional $\mathrm{B}$, constituindo um importante nó na rede urbana estadual. Na rede urbana nordestina, faz conexões com a metrópole de Recife $(P E)$, as capitais regionais A de Natal (RN), de São Luís (MA) e de João Pessoa (PB) e o centro regional $B$ de Juazeiro do Norte (CE). Recentemente, o município elevou o número de municípios sob sua influência imediata, passando de 25 para 34.

O estado do Rio Grande do Norte passou a ser dividido em três regiões geográficas intermediárias ou mesorregiões - Natal, Mossoró e Caicó - que, por sua vez, são subdivididas em 11 regiões geográficas imediatas ou microrregiões. Entre estas, está a região geográfica imediata de Pau dos Ferros, a primeira do estado em número de municípios, à frente da região imediata da capital do estado, Natal, com 24 municípios.

A região do Alto Oeste Potiguar (Figura 2) é um espaço formado por 34 (trinta e quatro) municípios, com população total de 226.272 habitantes (IBGE, 2010) e com grau de urbanização de 67\%. Dos municípios da região, a grande maioria (29 municípios) está situada na faixa de até 10.000 habitantes, possuindo $62 \%$ da população; ou seja, apenas 5 municípios possuíam população entre 10.001 e 30 mil habitantes e concentravam 
Figura 2 - Região geográfica de Pau dos Ferros, 2017

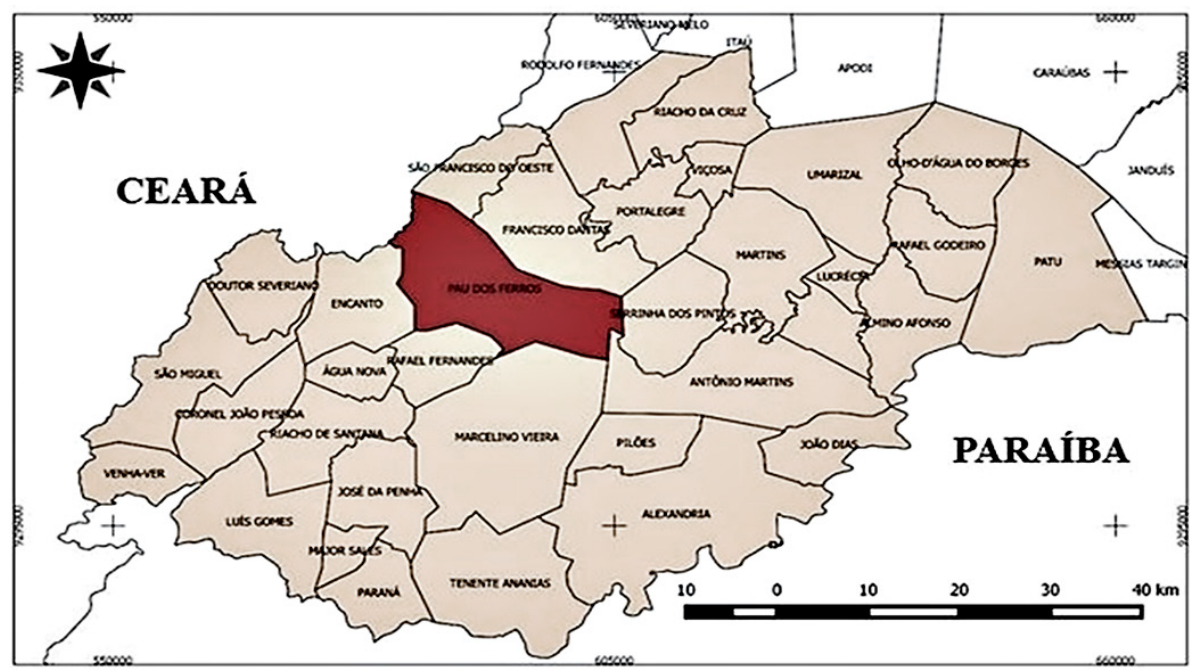

Fonte: Base cartográfica (IBGE, 2010). Elaboração própria.

38\% da população, não existindo na região, até o Censo de 2010, nenhum município com população acima de 30 mil habitantes. A não ser Pau dos Ferros, que, segundo o IBGE, teve sua população estimada em 30.394 habitantes em 2019.

Com relação à área de influência, a de Pau dos Ferros estende-se por 55 municípios 42 no próprio estado, 9 na Paraíba e 4 no Ceará, segundo Dantas (2014). Devido a isso, a cidade alcançou o terceiro nível na hierarquia urbana estadual, após Natal e Mossoró, ainda que conte com uma população inferior a Assu, que possui mais de 50 mil habitantes, e Caicó, que possui mais de 60 mil habitantes.

Do ponto de vista econômico, o Produto Interno Bruto (PIB) da região do Alto Oeste Potiguar concentra-se basicamente no setor terciário, que representa, em média, $87 \%$ do total do Valor Adicionado Bruto (VAB), conforme mostrado no Gráfico 1. Acrescente-se que, dentro do terciário, a maior participação é do setor público (administração pública, saúde, educação e seguridade social), responsável por, aproximadamente, $57 \%$ do PIB da região em 2014 (IBGE, 2018). 
Gráfico 1 - Alto Oeste Potiguar-RN:

Distribuição Percentual do Valor Adicionado Bruto (VAB)

do PIB a preços correntes, período 2003-2014

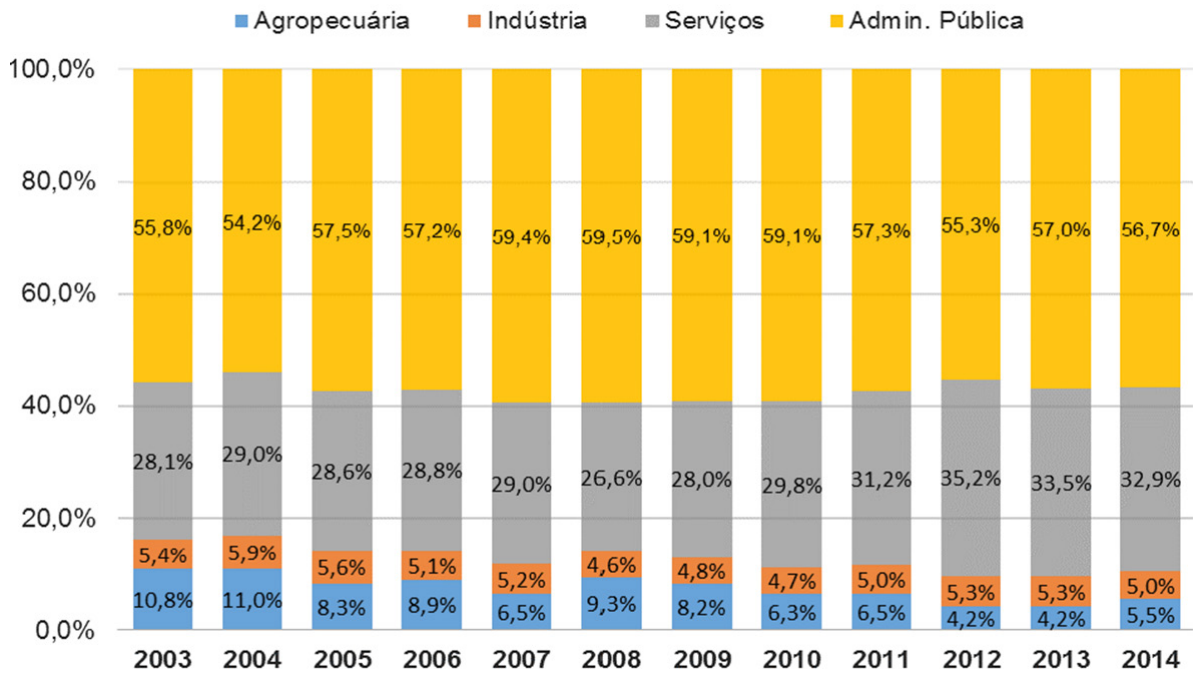

Fonte: IBGE (PIB dos municípios, 2018). Elaboração própria.

A importância regional da cidade de Pau dos Ferros não se dá pelo fato de possuir uma população majoritariamente urbana $(92,09 \%)$, mas econômica. Seu setor de serviços (privado) e comércio é mais significativo que nas demais cidades da região ( $55 \%$ em média), favorecendo a polarização que exerce sobre os pequenos municípios que a procuram para satisfação das necessidades educacionais, de saúde, financeiras e outras. $O$ setor público, sozinho, tem participação de 35\% no PIB municipal, de acordo com o IBGE.
Quanto à distribuição da população ocupada municipal, regional e estadual (Tabela 1), verifica-se o crescimento do emprego com carteira de trabalho assinada, que saltou, em Pau dos Ferros, de 19,3\%, no ano 2000, para $27 \%$ em 2010, apesar de ainda se situar abaixo da taxa do estado (RN), que foi de $38,1 \%$ em 2010. No entanto, o mercado de trabalho em Pau dos Ferros diferencia-se dos demais municípios da região do Alto Oeste em relação ao número de trabalhadores com carteira de trabalho assinada: possuía, em 2010, 27\% dos trabalhadores nessa condição, enquanto todo o Alto Oeste possuía 13,9\%. 
Tabela 1 - Pau dos Ferros, Alto Oeste Potiguar e RN:

Distribuição da população ocupada por posição

na ocupação no trabalho principal, 2000/2010

\begin{tabular}{|c|c|c|c|c|c|c|}
\hline \multirow[b]{2}{*}{ Especificação } & \multicolumn{3}{|c|}{ Ano 2000} & \multicolumn{3}{|c|}{ Ano 2010} \\
\hline & $\begin{array}{l}\text { Pau dos } \\
\text { Ferros }\end{array}$ & $\begin{array}{l}\text { Alto Oeste } \\
\text { Potiguar }^{1}\end{array}$ & RN & $\begin{array}{l}\text { Pau dos } \\
\text { Ferros }\end{array}$ & $\begin{array}{l}\text { Alto Oeste } \\
\text { Potiguar }\end{array}$ & RN \\
\hline Total & 100,0 & 100,0 & 100,0 & 100,0 & 100,0 & 100,0 \\
\hline Empregado com carteira assinada & 19,3 & 13,5 & 30,3 & 27,0 & 13,9 & 38,1 \\
\hline Empregado militar e funcionário público & 8,1 & 6,5 & 6,6 & 8,3 & 5,4 & 6,5 \\
\hline Empregado sem carteira assinada & 34,7 & 20,5 & 26,6 & 35,9 & 39,6 & 24,9 \\
\hline Não remunerado & 3,5 & 8,6 & 3,9 & 2,1 & 3,7 & 1,9 \\
\hline Trabalhador de subsistência & 6,5 & 34,4 & 8,3 & 3,7 & 17,7 & 6,5 \\
\hline Empregador & 1,4 & 0,6 & 2,1 & 1,8 & 0,8 & 1,5 \\
\hline Conta própria & 26,5 & 15,7 & 22,1 & 21,2 & 18,9 & 20,6 \\
\hline
\end{tabular}

Fonte: IBGE. Censos Demográficos. Elaboração própria.

Nota 1: outros municípios da região, exclusive Pau dos Ferros-RN.

Observa-se, adicionalmente, uma pequena redução na participação do trabalho por conta própria e um suave aumento da participação na ocupação de empregador em Pau dos Ferros, bem como uma queda generalizada dos trabalhadores de subsistência, que produzem para autoconsumo, o que indica que pode ter havido certa recuperação da renda local no período, devido à melhora da posição na ocupação.

Para corroborar os dados acima, utilizam-se as informações contidas na Relação Anual de Informações Sociais (Rais) para o período 2000-2015, mais recente. Constata-se, conforme a Tabela 2, uma ampliação do terciário de Pau dos Ferros após o ano 2000, momento em que começa a expansão do emprego formal no Brasil e há o aumento dos serviços públicos essenciais, notadamente de educação superior e saúde.
No período 2000-2010, a taxa de crescimento do emprego formal foi de $102,5 \%$ e, no período mais recente, 2010-2015, cresceu $24,2 \%$, de acordo com a Rais. O setor da Administração Pública, em Pau dos Ferros, representava mais da metade do emprego formal no ano 2000 , com $57,3 \%$ da participação total. Enquanto a participação relativa caía, de 34,8\% em 2010 para 31,3\% em 2015; em termos absolutos, crescia. Já o Comércio obteve um crescimento mais expressivo, em termos tanto absolutos quanto relativos, saltando de $21,9 \%$, em 2000 , para $41,0 \%$ em 2015 , considerando-se a participação desse setor no total do emprego formal de cada ano. Nos Serviços, a participação passou de 13,0\% em 2000 para $18,9 \%$ em 2015. Comércio e Serviços foram os segmentos com maior crescimento de empregos formais, demonstrando o maior dinamismo das atividades econômicas urbanas. 
Tabela 2 - Pau dos Ferros-RN: empregos formais nos setores da economia (2000-2015)

\begin{tabular}{|c|c|c|c|c|}
\hline Setor/Subsetor de Atividade & 2000 & 2005 & 2010 & 2015 \\
\hline $\begin{array}{l}\text { Industria de transformação } \\
\text { - Ind. Papel e Gráfica } \\
\text { - Ind. Alimentos e Bebidas } \\
\text { - Outros }\end{array}$ & $\begin{array}{r}20 \\
3 \\
16 \\
1\end{array}$ & $\begin{array}{r}80 \\
3 \\
72 \\
5\end{array}$ & $\begin{array}{r}122 \\
26 \\
73 \\
23\end{array}$ & $\begin{array}{r}131 \\
14 \\
96 \\
21\end{array}$ \\
\hline Serviços ind. de util. pública & 61 & 42 & 52 & 155 \\
\hline Construção civil & 26 & 30 & 47 & 28 \\
\hline $\begin{array}{l}\text { Comércio } \\
\text { - Comércio Varejista } \\
\text { - Comércio Atacadista }\end{array}$ & $\begin{array}{r}311 \\
246 \\
65\end{array}$ & $\begin{array}{l}597 \\
479 \\
118\end{array}$ & $\begin{array}{r}1.098 \\
931 \\
167\end{array}$ & $\begin{array}{r}1.462 \\
1.207 \\
255\end{array}$ \\
\hline $\begin{array}{l}\text { Serviços } \\
\text { - Instituição Financeira } \\
\text { - Adm. Técnica Profissional } \\
\text { - Transporte e Comunicações } \\
\text { - Serviço [alojamento, alimentação, reparos, comunicação] } \\
\text { - Serviços [médicos, odontológicos, veterinários] } \\
\text { - Ensino }\end{array}$ & $\begin{array}{r}185 \\
59 \\
9 \\
15 \\
28 \\
63 \\
11\end{array}$ & $\begin{array}{r}319 \\
44 \\
17 \\
19 \\
64 \\
73 \\
102\end{array}$ & $\begin{array}{r}552 \\
60 \\
73 \\
55 \\
151 \\
86 \\
127\end{array}$ & $\begin{array}{r}674 \\
80 \\
68 \\
96 \\
196 \\
126 \\
108\end{array}$ \\
\hline Administração pública & 812 & 673 & 999 & 1.115 \\
\hline Agricultura & 3 & 0 & 2 & 1 \\
\hline Total (Obs.: exclui atividades sem especificação) & 1.418 & 1.741 & 2.872 & 3.566 \\
\hline
\end{tabular}

Fonte: MTE (2016).

Acrescente-se que os setores de comércio, serviços e administração pública, somados, possuíam os maiores valores absolutos em termos de empregos gerados no ano 2000, quando concentravam $92 \%$ do emprego formal em Pau dos Ferros. Ao longo dos anos, contudo, o número de empregos nos subsetores de ensino e de serviços médicos cresceu. Esse aumento também se deu nos subsetores de serviços privados de alojamento, alimentação, reparos e comunicação, serviços de transportes e técnico-administrativos. Esses dados corroboram que as atividades terciárias urbanas foram as que mais cresceram.
Os dados acima apresentados ajudam a entender que o crescimento pelo qual passou a economia brasileira no período 2000 2014, com expansão dos serviços públicos, valorização do salário-mínimo, aumento da formalização do trabalho e incentivos ao crédito, rebateu na expansão do emprego formal urbano, dinamizando, também, os mercados das pequenas e médias cidades do interior do Nordeste.

Nesse sentido, é possível afirmar que a região do Alto Oeste Potiguar se insere analiticamente dentro de um quadro de realidades espaciais nordestinas em que a urbanização 
foi adquirindo um papel determinante na economia regional, especialmente quando a ação do Estado, notadamente a de âmbito federal, manifestou-se via crescimento do gasto público e demais políticas públicas implementadas no período 2003-2014. No caso de Pau dos Ferros, a ação do Estado ganha um caráter particular, o que é analisado a seguir.

\section{A influência do papel do Estado na centralidade regional de Pau dos Ferros/RN}

Como visto na seção anterior, a cidade de Pau dos Ferros é geograficamente privilegiada, fazendo parte de um entroncamento viário regionalmente relevante. Por esse e outros motivos, foi escolhida pelo governo federal para abrigar alguns importantes órgãos públicos. A estrutura de serviço público federal chegou à região semiárida há muito tempo, especialmente para fazer frente a situações dramáticas de vulnerabilidade social devido à ocorrência de longos períodos de estiagem. Isso favoreceu estruturalmente a cidade ao provê-la de recursos, órgãos de planejamento e execução de obras de interesse social, concentrando serviços públicos.

A instalação de uma filial do Departamento Nacional de Obras Contra as Secas (Dnocs) $^{4}$ na cidade em 1952, juntamente com um escritório do Banco do Nordeste do Brasil (BNB), que passaria a operar como agência no ano de 1955, são exemplos do tipo de presença que o Estado passou a ter, dando sustentação a políticas públicas em toda a zona semiárida adjacente.
É sabido que a instalação de instituições e órgão públicos estaduais e federais em cidades do interior do Brasil obedeceu a diferentes critérios políticos, mas, ao mesmo tempo, respondeu a planos e estratégias de desenvolvimento regional. No caso de Pau dos Ferros, como se constata no Quadro 1, a maior parte dessas instituições/órgãos foi instalada até o final dos anos 1970, em momentos variados, tendo como destaque os serviços financeiros e especializados. Considera-se ser este último um bom indicador para aferir, qualitativamente, o peso de sua área de influência.

Durante os anos 1990, os serviços de utilidade pública e essenciais foram reforçados no município, apesar de ter sido um momento de baixa provisão de serviços públicos. Recentemente, no período 2000-2013, uma série de serviços públicos essenciais foi instalada ou expandida. Ou seja, em pouco mais de 13 anos, uma série de serviços com impacto direto e amplo na vida do cidadão foi ofertada na região do Alto Oeste Potiguar, reforçando o papel de Pau dos Ferros como locus de articulação regional.

Verifica-se, através do Quadro 1, que, antes mesmo da década de 1950, já existiam na cidade de Pau dos Ferros outros órgãos federais importantes. Além das agências de Correios (instalada desde 1861) e de Telégrafos (instalado em 1908), que seriam fundidas em 1932 em uma única empresa nacional, existiam na cidade um órgão arrecadador da Receita Federal, instalado em 1929, e uma unidade do IBGE, instalada em 1936. Todas essas instituições públicas federais, além de outras estaduais, proviam uma estrutura básica de serviços que atendia as cidades situadas na zona oeste do estado, próximas e tributárias de Pau dos Ferros. 
Quadro 1 - Instituições e Órgãos Públicos Estaduais e Federais localizados na cidade de Pau dos Ferros-RN, segundo o ano de instalação e/ou expansão

\begin{tabular}{|c|c|c|c|c|c|}
\hline \multicolumn{6}{|c|}{ Até o final dos anos 1970} \\
\hline \multirow{2}{*}{\multicolumn{2}{|c|}{ Tipo de serviço }} & \multirow{2}{*}{ Instituição/Órgão } & \multicolumn{2}{|c|}{ Esfera } & \multirow{2}{*}{$\begin{array}{l}\text { Instalação/ } \\
\text { Expansão }\end{array}$} \\
\hline & & & Estadual & Federal & \\
\hline \multicolumn{2}{|l|}{ Financeiros } & $\begin{array}{l}\text { Banco do Nordeste do Brasil } \\
\text { Caixa Econômica Federal } \\
\text { Banco do Brasil }\end{array}$ & $\begin{array}{l}- \\
- \\
-\end{array}$ & $\begin{array}{l}\mathrm{x} \\
\mathrm{x} \\
\mathrm{x}\end{array}$ & $\begin{array}{l}1955 \\
1978 \\
1978\end{array}$ \\
\hline \multicolumn{2}{|c|}{ Especializados } & $\begin{array}{l}\text { Correios (CDD) } \\
\text { Coletoria Estadual } \\
\text { Receita Federal } \\
\text { IBGE }\end{array}$ & $\begin{array}{l}- \\
x \\
- \\
-\end{array}$ & $\begin{array}{l}\mathrm{x} \\
- \\
\mathrm{x} \\
\mathrm{x}\end{array}$ & $\begin{array}{l}1861 \\
1917 \\
1929 \\
1936\end{array}$ \\
\hline \multicolumn{2}{|c|}{ Utilidade Pública } & $\begin{array}{l}\text { Dnocs } \\
\text { Caern } \\
\text { Cosern } \\
\text { DER }\end{array}$ & $\begin{array}{l}- \\
x \\
x \\
x\end{array}$ & $\begin{array}{l}x \\
x \\
x \\
x\end{array}$ & $\begin{array}{l}1952 \\
1970 \\
1970 \\
1972\end{array}$ \\
\hline \multirow{4}{*}{$\begin{array}{l}\text { Públicos } \\
\text { essenciais }\end{array}$} & Saúde & $\begin{array}{l}\text { Hospital Centenário } \\
\text { Maternidade "Santa Luzia" }\end{array}$ & $\begin{array}{l}x \\
x\end{array}$ & $\begin{array}{l}- \\
-\end{array}$ & $\begin{array}{l}1956 \\
1961\end{array}$ \\
\hline & Educação & UERN & $x$ & - & 1976 \\
\hline & Justiça & Tribunal de Justiça do RN & $x$ & - & 1953 \\
\hline & Segurança Pública & Batalhão 7ํ da PM e presídio & $x$ & - & 1941 \\
\hline \multicolumn{6}{|c|}{ Durante os anos 1990} \\
\hline \multirow{2}{*}{\multicolumn{2}{|c|}{ Tipo de serviço }} & \multirow{2}{*}{ Instituição/Órgão } & \multicolumn{2}{|c|}{ Esfera } & \multirow{2}{*}{$\begin{array}{c}\text { Instalação/ } \\
\text { Expansão }\end{array}$} \\
\hline & & & Estadual & Federal & \\
\hline \multicolumn{2}{|c|}{ Utilidade Pública } & $\begin{array}{l}\text { Detran } \\
\text { INSS }\end{array}$ & $\begin{array}{l}x \\
-\end{array}$ & $\bar{x}$ & $\begin{array}{l}1990 \\
1992\end{array}$ \\
\hline \multirow{3}{*}{$\begin{array}{l}\text { Públicos } \\
\text { essenciais }\end{array}$} & Saúde & Hospital Regional & $x$ & - & 1990 \\
\hline & Educação & XV Direc (ensino médio) & $x$ & - & 1999 \\
\hline & Justiça & Justiça do Trabalho & - & $x$ & 1993 \\
\hline \multicolumn{6}{|c|}{ Desde 2000 até atualmente } \\
\hline \multirow{2}{*}{\multicolumn{2}{|c|}{ Tipo de serviço }} & \multirow{2}{*}{ Instituição/Órgão } & \multicolumn{2}{|c|}{ Esfera } & \multirow{2}{*}{$\begin{array}{c}\text { Instalação/ } \\
\text { Expansão }\end{array}$} \\
\hline & & & Estadual & Federal & \\
\hline Especializac & & Central do Cidadão & $x$ & - & 2005 \\
\hline Utilidade $\mathrm{P}$ & & Idema & $x$ & - & 2013 \\
\hline \multirow{4}{*}{$\begin{array}{l}\text { Públicos } \\
\text { essenciais }\end{array}$} & Saúde & $\begin{array}{l}\text { VI Ursap } \\
\text { Unicat }\end{array}$ & $\begin{array}{l}x \\
x \\
\end{array}$ & - & $\begin{array}{l}2001 \\
2005 \\
\end{array}$ \\
\hline & Educação & $\begin{array}{l}\text { UERN } \\
\text { IFRN } \\
\text { Ufersa }\end{array}$ & $\begin{array}{l}x \\
- \\
-\end{array}$ & $\begin{array}{l}- \\
x \\
x\end{array}$ & $\begin{array}{l}2004 \\
2009 \\
2012\end{array}$ \\
\hline & Justiça & $\begin{array}{l}\text { Ministério Público } \\
\text { Justiça Eleitoral } \\
\text { Justiça Federal } \\
\text { Ministério Público Federal }\end{array}$ & $\begin{array}{l}x \\
- \\
- \\
-\end{array}$ & $\begin{array}{l}- \\
x \\
x \\
x\end{array}$ & $\begin{array}{l}2008 \\
2010 \\
2011 \\
2013\end{array}$ \\
\hline & Segurança Pública & $\begin{array}{l}\text { Polícia Civil e Presídio } \\
\text { Corpo de Bombeiros } \\
\text { Batalhão 70 da PM e presídio }\end{array}$ & $\begin{array}{l}\mathrm{x} \\
\mathrm{x} \\
\mathrm{x}\end{array}$ & $\begin{array}{l}- \\
-\end{array}$ & $\begin{array}{l}2006 \\
2011 \\
2000\end{array}$ \\
\hline
\end{tabular}

Fonte: elaboração própria com base em pesquisa de campo, em 2017. 
Os anos 1950 foram um marco nas ações de estruturação urbana da cidade, pois é quando ocorre a montagem da estrutura de serviços públicos essenciais para atender a população local e os municípios circunvizinhos. Mas, será a partir dos anos 1970, concomitantemente às transformações na economia e na urbanização do estado, que a cidade, mais urbanizada e com uma estrutura ocupacional baseada no terciário, aumentará a sua influência na região.

A instalação de uma unidade de educação superior, em meados dos anos 1970, será outro marco importante. Por meio do decreto n. 15/76, de 28 de setembro de 1976, foi criado o Campus Avançado de Pau dos Ferros, depois denominado "Professora Maria Elisa de Albuquerque Maia" (Cameam), vinculado à Universidade Regional do Rio Grande do Norte (URRN), ${ }^{5}$ sediada em Mossoró. O Campus de Pau dos Ferros passava a funcionar com três cursos, sendo dois de licenciatura (Letras e Pedagogia) e um bacharelado (Ciências Econômicas), com oferta de 135 vagas, 45 para cada curso.

O setor público da região do Alto Oeste foi se ampliando por conta dos processos de emancipação e/ou criação ${ }^{6}$ de novos municípios na região entre as décadas de 1950-1960. A partir dessa época, Pau dos Ferros passava a funcionar como um nó importante na rede urbana do RN, por conta da oferta de serviços essenciais e especializados (educação, saúde, financeiros) para toda sua área de influência direta e para as pequenas cidades nos estados circunvizinhos do Ceará e da Paraíba.

A estrutura de serviços públicos essenciais em Pau dos Ferros - saúde, educação, justiça, segurança - seria novamente ampliada nos 1990, mas foi a partir dos anos 2000 que serviços públicos de saúde e de educação superior mais se expandiram na cidade. Os serviços privados, inclusive, acompanharam o ritmo de crescimento e, de forma complementar, ampliaram a oferta de educação e saúde, reforçando ainda mais o sistema.

É importante salientar que, desde 2000, essa expansão tornou a região Nordeste mais integrada e urbanizada. Ela foi interiorizada para a zona semiárida, a que mais se beneficiou das políticas públicas nacionais ${ }^{7}$ durante os governos Lula e Dilma (2003-2016), contribuindo para a redução nas desigualdades. A combinação de gastos públicos (despesas e investimentos) com políticas públicas direcionadas promoveu maior integração urbano-regional, etapa prévia a qualquer processo sustentado de desenvolvimento regional.

O provimento desses serviços constitui um dos primeiros fatores determinantes para o fortalecimento da estrutura econômica e para a aquisição de mais funções urbanas por parte de Pau dos Ferros na região, passando a ser considerada uma cidade média. Observa-se que esse conceito é frequentemente entendido a partir de um ponto de vista interno, em que o funcionamento de uma cidade e a melhoria do seu padrão de vida são questões relevantes. São poucos os trabalhos que combinam o ponto de vista interno com o externo, discutindo o seu papel regional.

Há importantes contribuições sobre o papel das cidades médias em várias regiões do Brasil, ${ }^{8}$ mas as análises, na maioria das vezes, partem de estudos de casos isolados, sem levar em conta a influência efetiva da cidade na região em que se situa. Corrêa (2007; 2017), por exemplo, chama a atenção para a cidade média como um "nó" importante numa rede urbana, em que é possível pensá-la 
em interação com outras num determinado contexto regional, exercendo funções combinadas: "função de lugar central, de drenagem e consumo da renda fundiária, industrial, portuária e função de capital político-administrativa" (2017, p. 30). Já Sposito (2007) argumenta ser mais útil a classificação de "cidade intermediária" para designar mais apropriadamente o papel que essas cidades realmente desempenham numa área de influência.

A categorização de cidade intermediária seria mais útil no presente caso, por ser mais adequada à análise dos processos de integração regional em regiões semiáridas nordestinas, levando-se em conta, primeiro, o grau de densidade urbana mínima (qualidades endógenas) para atender uma região mais ampla e, segundo, o nível de intensidade das relações interurbanas (qualidades exógenas) capaz de articular as cidades de uma mesma região ou de uma região ampla, indo, inclusive, além da região imediata.

Dessa forma, Pau dos Ferros, por polarizar muitas cidades no estado do Rio Grande do Norte e até em outros estados vizinhos, como Paraíba (PB) e Ceará (CE), projeta-se como um nó relevante da rede urbana potiguar quando pensamos na organização de uma rede mais interiorizada e, simultaneamente, articulada a uma região mais ampla, ou seja, como uma cidade intermediária. Contudo, é preciso ir além de sua posição, sua forma, e avançar sobre seu conteúdo, qual seja: a densidade urbana e a intensidade das relações.

Chama a atenção o fato de uma cidade de cerca de 30 mil habitantes, como Pau dos Ferros, obter destaque regional, ainda que não se enquadre inteiramente aos critérios comumente utilizados para definir uma cidade média como um conjunto mais ou menos combinado de qualidades endógenas. Seguramente, a sua classificação como cidade intermediária, um conjunto articulado de qualidades endógenas e exógenas, é mais relevante, especialmente quando o objetivo é a integração urbano-regional em regiões cuja urbanização surgiu e evoluiu de forma dispersa.

O que torna Pau dos Ferros uma cidade intermediária é o provimento de equipamentos e de serviços públicos, facultando, à cidade, um papel proeminente na rede urbana potiguar e nordestina. Durante a década de 1990, o principal equipamento de saúde para atender à demanda regional era o Hospital Regional de Pau dos Ferros (Hospital Dr. Cleodon Carlos de Andrade), inaugurado no ano de 1990. Porém, na década de 2000, foram instaladas várias clínicas particulares, nas mais diversas especialidades, as quais passaram também a atender pelo Sistema Único de Saúde (SUS), via convênio com as prefeituras municipais da região. ${ }^{9}$

A descentralização dos recursos do SUS para os municípios contribuiu para o aumento de programas e projetos voltados para a saúde da população regional, o que possibilitou o surgimento de clínicas e diversificação dos serviços ofertados a partir da cidade de Pau dos Ferros. Os dados da Tabela 3 mostram a evolução recente do número de estabelecimentos de saúde na cidade, com base nas informações disponíveis no Cadastro Nacional de Estabelecimentos de Saúde (CNES). ${ }^{10}$

Os dados indicam que, entre 2007 e 2017, conforme anos selecionados, a oferta de estabelecimentos públicos estaduais de saúde expandiu em 3,8\% a.a.; já a oferta de estabelecimentos públicos municipais de saúde expandiu em 2,7\% a.a. Quanto à oferta de estabelecimentos associativos e privados, esta 
Tabela 3 - Taxa de crescimento anual dos estabelecimentos de saúde em Pau dos Ferros-RN

\begin{tabular}{l|c|c|c|c|c|c|c}
\hline \multirow{2}{*}{ Estabelecimentos } & \multicolumn{9}{c|}{ Anos } & Crescimento \\
Anual - \%
\end{tabular}

Fonte: Datasus/CNES. Elaboração própria.

Nota 1: percentual calculado com base no ano de 2010.

cresceu $7,0 \%$ a.a. e 7,6\% a.a., respectivamente, acima do crescimento médio anual total, de $6,7 \%$ a.a. Claro que há diferenças importantes entre os equipamentos quanto ao porte e à finalidade, mas a ênfase aqui é no crescimento da oferta do serviço, tornando-o disponível ao acesso da população.

Com a expansão dos serviços especializados, de utilidade pública e, principalmente, com a ampliação da oferta dos serviços da saúde em Pau dos Ferros, no período 2000-2017, alguns estudos passam a qualificá-la de cidade média e a salientar a importância de seu papel na rede urbana (Dantas, 2014). 0 fluxo crescente de pessoas de outros municípios da região de influência de Pau dos Ferros, dentro do estado do $\mathrm{RN}$, e até de outros municípios de estados vizinhos (CE e PB) em busca de bens e serviços (públicos e privados) - saúde, educação superior, principalmente - é que vai consolidando, segundo esses estudos, a cidade de Pau dos Ferros na sua área de influência direta. ${ }^{11}$

Contudo, o indicador que melhor qualifica e dá relevância à importância regional de Pau dos Ferros é o da expansão da educação superior nesta última década. Segundo Vieira (2017, p. 281), a educação superior é responsável por dois tipos de efeitos (ou externalidades positivas): efeito dispêndio, em função do aumento na renda e no emprego locais, dos gastos de consumo de estudantes, funcionários e professores e dos investimentos das universidades em serviços e equipamentos; e efeito conhecimento, via os benefícios gerados pelas atividades finalísticas da universidade na região, ao produzir e difundir conhecimento. 


\section{A expansão do ensino superior público e a dinâmica regional de Pau dos Ferros}

A expansão do ensino superior, no período 2003-2014, pode ser apontada como o fator mais decisivo para o aumento da importância regional da cidade de Pau dos Ferros. Como dito anteriormente, é nesse sentido que ela pode ser compreendida como uma cidade intermediária, ou seja, pelos níveis de articulação que passa a exercer na região do Alto Oeste Potiguar e demais espaços inter-regionais, a partir do incremento da função de provimento de equipamentos e serviços públicos, o que contribui para acrescentar-Ihe qualidades endógenas e exógenas.

O maior provimento de educação de nível superior deu-se incialmente com a expansão na oferta de cursos superiores no campus da UERN de Pau dos Ferros, única Instituição de Ensino Superior (IES) existente no município até o ano de 2008. No ano de 2003, havia, no campus da UERN de Pau dos Ferros, ${ }^{12}$ apenas os três cursos de graduação - Letras, Pedagogia e Ciências Econômicas -, os mesmos desde a sua fundação em 1976. A partir do ano de 2004, passavam a funcionar mais quatro cursos de graduação - Administração, Educação Física, Enfermagem e Geografia -, com o curso de Administração funcionando em horário noturno e os demais em turnos matutino e vespertino. Nesse mesmo ano, o curso de Letras também foi ampliado, passando a oferecer Letras com Espanhol e Letras com Português no turno matutino; permanecendo, no turno noturno, o curso de Letras com Inglês. Assim, o campus da UERN de Pau dos Ferros elevou sua oferta para nove cursos de graduação regulares.
Em seguida, ocorreu a ampliação da oferta de pós-graduação stricto sensu, com a inauguração de cursos de mestrado. 0 primeiro deles foi o curso de mestrado acadêmico em Letras, no ano de 2008. Na época, a cidade de Pau dos Ferros ganhava destaque nacional como a menor cidade do Brasil a ofertar um curso de mestrado acadêmico. Logo após viriam mais dois mestrados, um profissional em Letras e um mestrado acadêmico em Ensino. A oferta de cursos de pós-graduação no campus da UERN em Pau dos Ferros continuou a aumentar nos anos seguintes: em 2014, ocorreu a instalação do doutorado em Letras; no ano de 2015, foi instalado o mestrado acadêmico em Planejamento e Dinâmicas Territoriais do Semiárido (Plandites), no departamento de Economia; e, mais recentemente, em 2016, teve início o Doutorado Interinstitucional em Desenvolvimento Urbano, em parceria com a Universidade Federal de Pernambuco. Em suma, o campus da UERN em Pau dos Ferros passou a ofertar 9 cursos de graduação e 6 cursos de pós-graduação stricto sensu, sendo 4 de mestrado e 2 de doutorado.

Informações recentes obtidas junto à secretaria $^{13}$ do Cameam davam conta de que, somente no nível de graduação, o campus contava com 1.156 alunos ativos, provenientes de 47 municípios dos estados do Rio Grande do Norte, Paraíba e Ceará, conforme a Figura 3. Do total de alunos de graduação do campus de Pau dos Ferros, com vínculo ativo, a maioria era oriunda de 38 municípios do estado.

Somente o campus da UERN em Pau dos Ferros, dentre as Instituições de Ensino Superior (IES) públicas e privadas existentes na cidade, oferece pós-graduação stricto sensu, nível de mestrado e doutorado. E foi com a pós-graduação do campus da UERN que Pau dos 
Figura 3 - Origem dos alunos matriculados nos cursos de graduação, campus da UERN em Pau dos Ferros (2018)

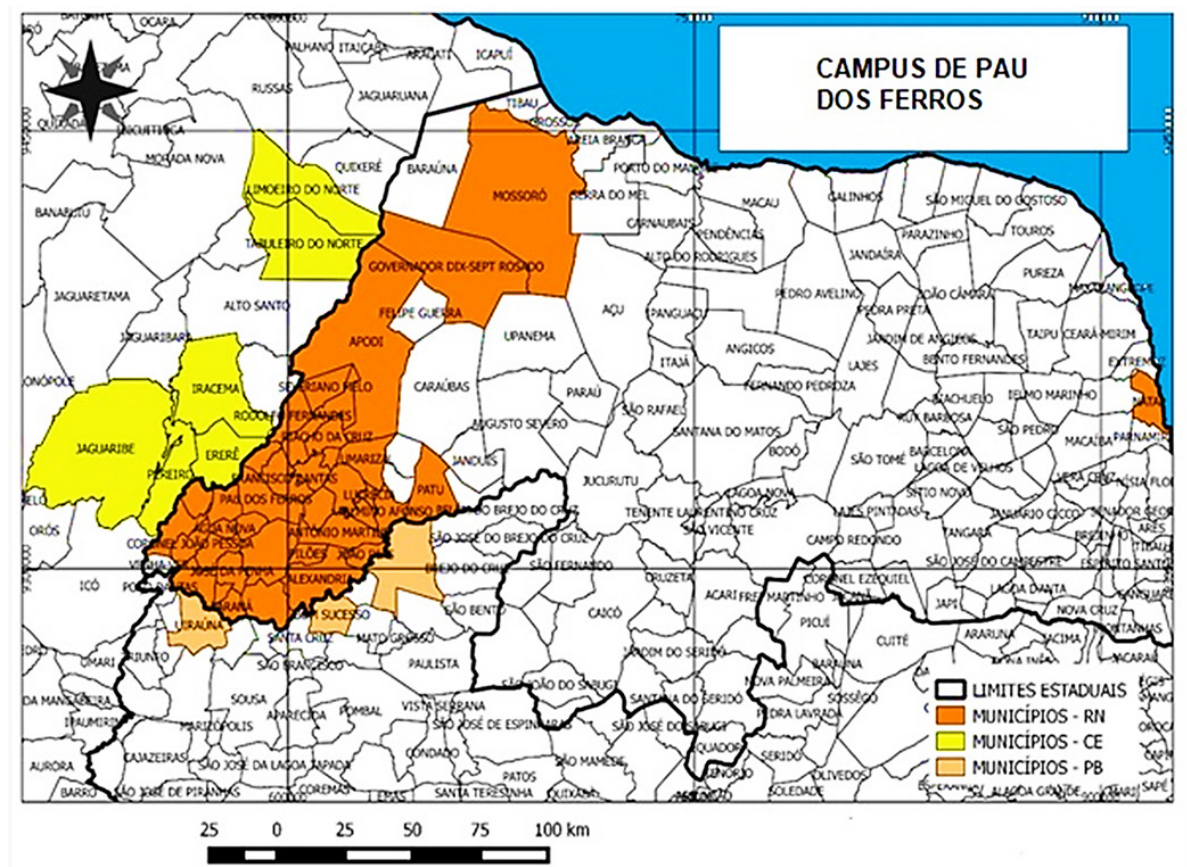

Fonte: UERN-Sigaa (2018). Elaboração própria.

Nota: constam do mapa apenas os 1.015 alunos com endereços cadastrados no sistema da UERN.

Ferros ganhou destaque em termos de abrangência territorial e de impacto regional. Segundo dados obtidos na secretaria do campus, referentes aos alunos da pós-graduação ${ }^{14}$ stricto sensu matriculados, existia um total de 265 alunos ativos, provenientes de 88 municípios, abrangendo cinco estados nordestinos: Rio Grande do Norte, Paraíba, Ceará, Pernambuco e Piauí. A Figura 4 mostra a origem dos alunos, por município, matriculados nos cursos de pós-graduação stricto sensu em Pau dos Ferros.

Do total de alunos matriculados na pós-graduação no campus da UERN em Pau dos
Ferros, o estado do RN possuía $62,3 \%$ do total, originados de 45 municípios; os demais estados (PB, CE, PE e PI) representavam a outra metade das localidades, 43 municípios, sendo $37,7 \%$ do total de alunos. Esses números revelam a importância da interiorização do ensino superior no Brasil, em geral, e no semiárido nordestino, em particular, ao mesmo tempo que colabora para aumentar a importância regional de Pau dos Ferros, notadamente devido à crescente importância do campus da UERN, que expandiu a oferta de cursos de graduação e de pós-graduação. 
Figura 4 - Origem dos alunos matriculados nos cursos de pós-graduação stricto sensu, campus da UERN em Pau dos Ferros (2018)

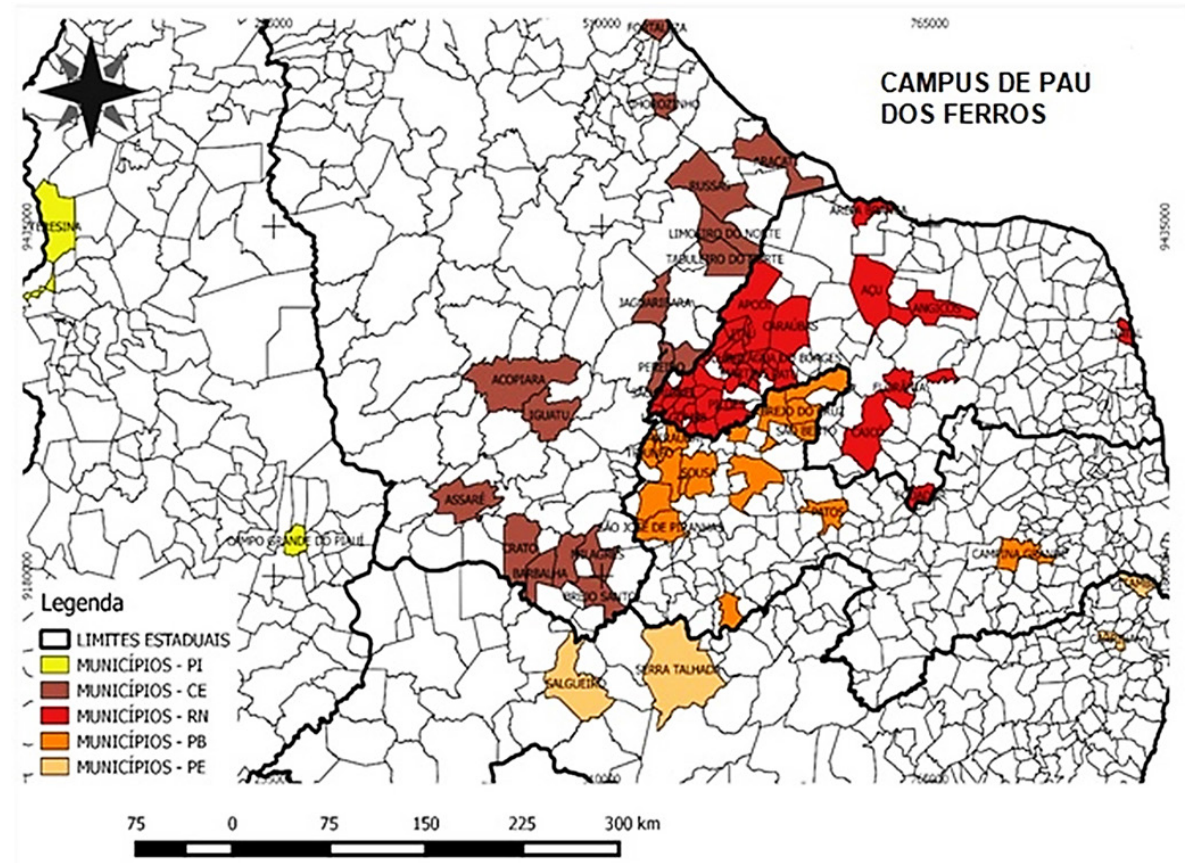

Fonte: UERN-Sigaa (2018). Elaboração própria.

A oferta de curso de pós-graduação constitui um fator de ampliação da área de influência de Pau dos Ferros em relação às cidades dos estados vizinhos, além de incorporar uma função característica de cidades intermediárias (Esteban e López, 1989) ao satisfazer a demanda ampla por educação e formação profissional no interior do País.

A cidade de Pau dos Ferros foi duplamente contemplada com essa interiorização: primeiro, com a instalação de um campus do Instituto Federal do Rio Grande do Norte (IFRN), ${ }^{15}$ em 2009, que funciona com ensino médio, nível técnico e ensino superior; e, segundo, com a entrada em operação do campus da Universidade Federal Rural do Semiárido (Ufersa), em 2012.

O campus do IFRN em Pau dos Ferros foi inaugurado em 2009. Está instalado num terreno cedido pela prefeitura, com área de $28.820 \mathrm{~m}^{2}$, localizado no bairro Chico Cajá, situado às margens da BR 405. Esse campus funciona atualmente com três cursos técnicos, dois de graduação e um de especialização. Os cursos técnicos são: Alimentos, Apicultura e Informática. 
Os cursos técnicos são oferecidos de forma integrada, ou seja, são cursados com o ensino médio. Os três cursos também são ofertados na modalidade subsequente, ou seja, para candidatos que já possuem ensino médio e desejam ter uma formação técnica/profissional. Os cursos de nível superior ofertados são: Tecnologia em Análise e Desenvolvimento de Sistemas e Química (licenciatura). 0 curso de especialização ofertado é o de Ensino de Ciências Naturais e Matemática. Em relação aos dois cursos de graduação ofertados - licenciatura em Química e Tecnologia em Análise e Desenvolvimento de Sistemas (Tads) -, informações obtidas junto à secretaria do campus em Pau dos Ferros deram conta de um total de 179 alunos ativos provenientes de 43 municípios dos estados do Rio Grande do Norte, Paraíba e Ceará.

A maioria dos alunos $(87,2 \%)$ é do estado do RN, e Pau dos Ferros responde por 22,9\% do total. A Figura 5 mostra a origem dos alunos, por município, matriculados nos cursos de graduação do campus IFRN em Pau dos Ferros.

Figura 5 - Origem dos alunos matriculados nos cursos de graduação, campus do IFRN em Pau dos Ferros (2018)

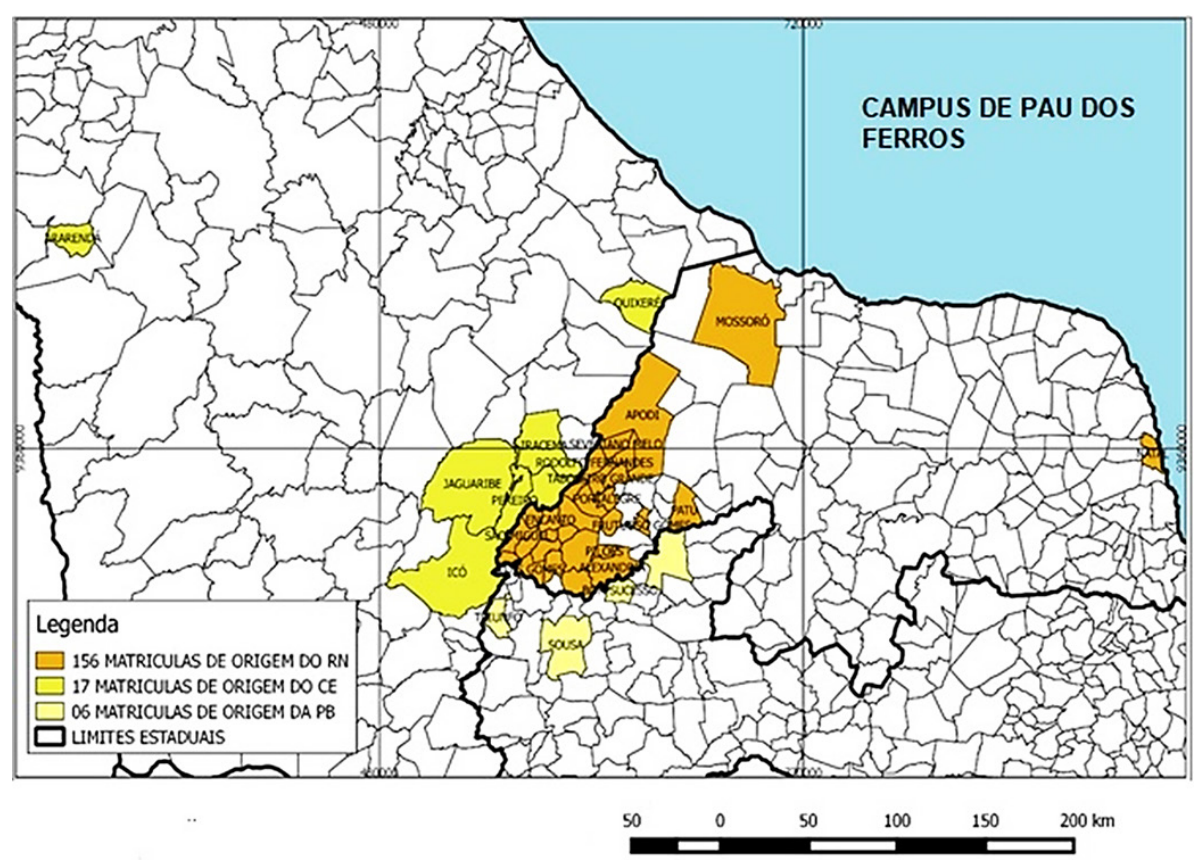

Fonte: IFRN-Sigaa (2018). Elaboração própria. 
Quanto ao campus da Universidade Federal Rural do Semiárido (Ufersa), ${ }^{16}$ este foi instalado no bairro São Geraldo em Pau dos Ferros, situado às margens da BR 226 (saída para o município de Francisco Dantas). 0 campus da Ufersa foi criado com a proposta inicial de quatro cursos: Engenharia Civil, Engenharia da Computação, Engenharia Mecânica e Telecomunicação (Figura 6). Quando do início das atividades, esses cursos foram modificados, conforme as necessidades da região e a existência de outras universidades na cidade. Atualmente, o campus oferta sete cursos de bacharelado em Ciência e Tecnologia, Tecnologia da Informação, Arquitetura e Urbanismo, Engenharia Civil, Engenharia de Computação, Engenharia Ambiental e Sanitária e Engenharia de Software.

Conforme informações obtidas na secretaria do campus da Ufersa, em Pau dos Ferros existia um total de 1.249 alunos ativos provenientes de 125 municípios de 15 estados da federação: Rio Grande do Norte, Paraíba, Ceará, Piauí, Pernambuco, Maranhão e Bahia (do Nordeste); Pará, Acre, Roraima e Rondônia (do Norte); São Paulo, Rio de

Figura 6 - Origem dos alunos matriculados nos cursos de graduação, campus da Ufersa em Pau dos Ferros (2018)

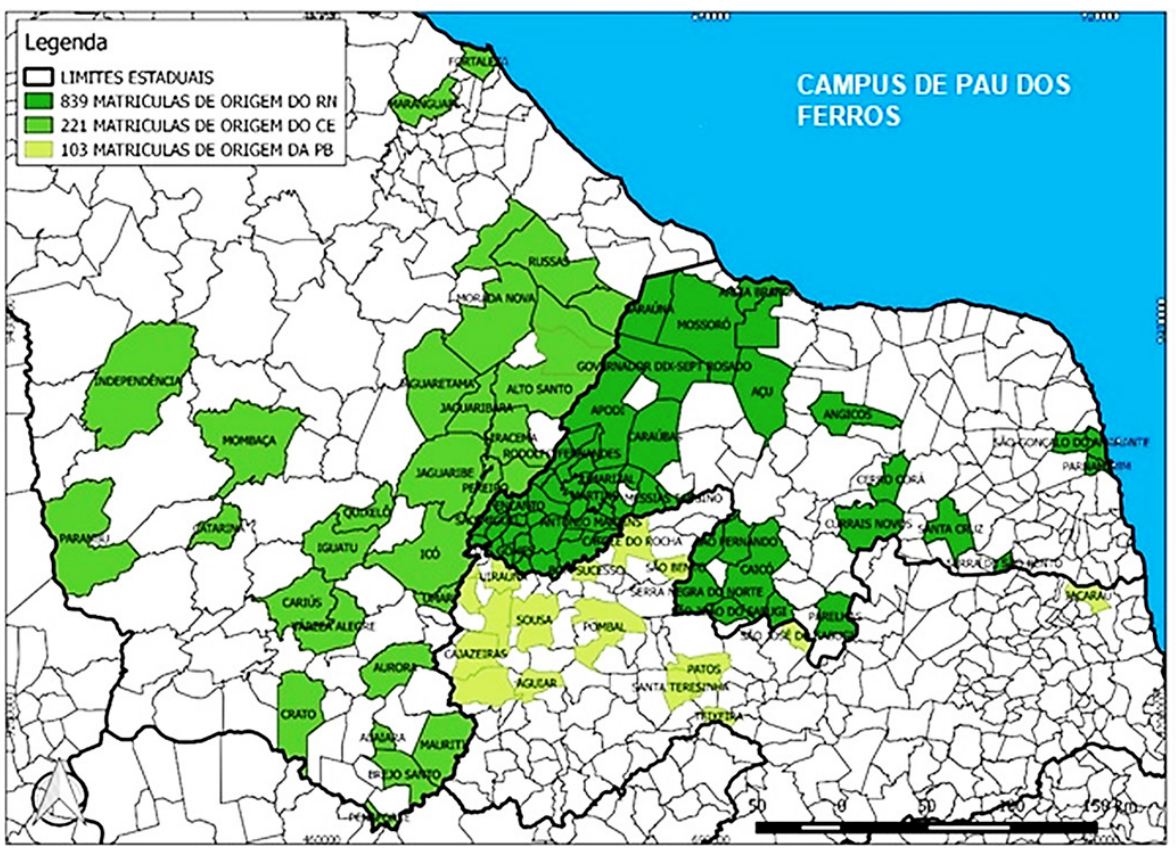

Fonte: UFERSA-Sigaa (2018). Elaboração própria.

Nota: estão representadas, no mapa, apenas as localidades dos estados do RN, PB e CE. 
Janeiro e Espírito Santo (do Sudeste); e Mato Grosso do Sul (do Centro-Oeste). Desse total de alunos, o RN possuía 70,5\%, o CE $18,5 \%$ e a PB 8,8\%\%; ou seja, os três estados fronteiriços respondiam por $97 \%$ do total de alunos da Ufersa.

Cabe enfatizar, de forma suplementar, que a política de expansão do ensino superior público na cidade de Pau dos Ferros também contribuiu para a criação e a expansão da oferta de ensino superior pelo setor privado, na esteira dos incentivos do Programa Universidade para Todos (Prouni) e do Programa de Financiamento Estudantil (Fies) do governo federal. As maiores faculdades privadas atuantes na cidade são a Faculdade Evolução Alto Oeste Potiguar (Facep) e a Anhanguera.

A faculdade Anhanguera, uma das marcas atualmente pertencentes ao grupo Kroton Educacional, iniciou suas atividades na cidade no ano de 2008. Em Pau dos Ferros-RN são oferecidos quatro cursos de graduação e dois de tecnólogos: bacharelado em Administração, Ciências Contábeis, Serviço Social; licenciatura em Pedagogia; tecnólogos em Marketing Digital, Recursos Humanos. ${ }^{17}$ Já a Facep, ${ }^{18}$ pertencente a empresários da cidade, iniciou suas atividades ofertando o primeiro curso superior em 2009. Atualmente, a faculdade conta com cinco cursos de graduação presencial ofertados: Administração (início em 2009), Direito (início em 2010), Psicologia e Pedagogia (início em 2013) e Enfermagem (início em 2017). A empresa conta ainda com mais dois cursos de pós-graduação nas áreas de Administração (Especialização em Gestão de Pessoas) e Direito (Especialização em Direito Constitucional e Direito Tributário).

A Figura 7 é uma síntese das anteriores e mostra o total de municípios de origem dos alunos nos três estados fronteiriços (RN, PB e CE) matriculados (e com endereços cadastrados) nos cursos de graduação das três IES públicas em Pau dos Ferros, no ano de 2018. São, ao todo, 2.346 alunos provenientes de 108 municípios.

Como se nota, desde 2012, a cidade de Pau dos Ferros passou a dispor de IES públicas e privadas que incrementaram as relações com a região e elegeram a função educação como altamente relevante para a sua integração urbano-regional. 0 surgimento e a ampliação de novos cursos de graduação e de pós-graduação deram densidade urbana ao município - uma vez que estes atraem novos profissionais e alunos de fora da cidade e do estado -, além de contribuírem para a dinamização da economia local e para dar intensidade à articulação entre cidades, haja vista o aumento da área de influência de Pau dos Ferros aos estados do Rio Grande do Norte (RN), Ceará (CE) e Paraíba (PB). 
Figura 7 - Origem dos alunos matriculados nos cursos de graduação das IES em Pau dos Ferros - UERN, IFRN e Ufersa provenientes dos estados do RN, CE e PB, 2018

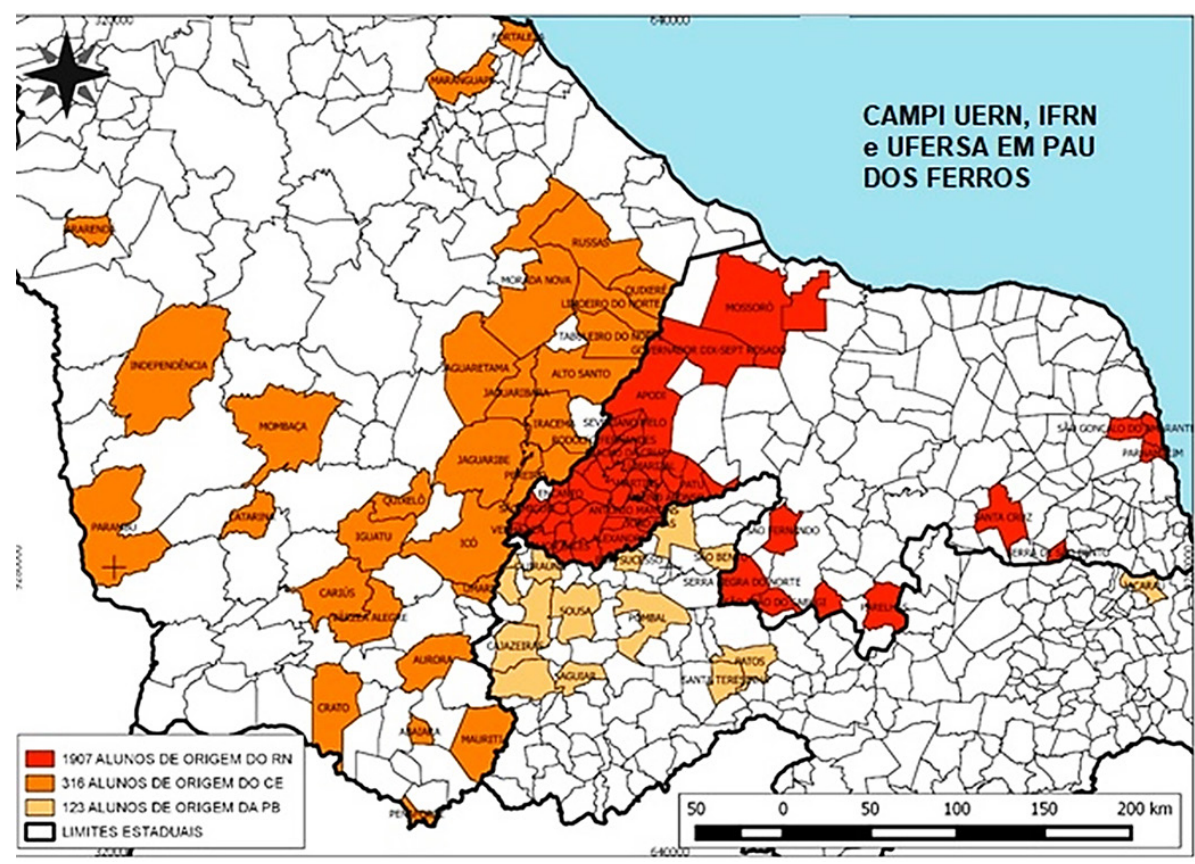

Fonte: Sigaa das IES: UERN (2018), IFRN (2018), Ufersa (2018). Elaboração própria. Nota 1: estão representadas, na figura, apenas as localidades dos estados do RN, PB e CE.

Nota 2: constam as localidades dos alunos com endereços cadastrados no sistema das respectivas IES.

\section{Considerações finais}

Os gastos públicos são ingrediente importante na dinâmica das pequenas e médias cidades brasileiras, mas sobretudo naquelas que se apresentam como cidades intermediárias. Ao se adotar essa noção para referir-se ao papel regional da cidade de Pau dos Ferros, buscou-se corroborar as características apontadas por Corrêa (2007; 2017) e Sposito (2007), chamando a atenção para a capacidade de articulação das cidades num determinado espaço, fruto de maior integração urbano-regional. No centro desse processo, está o gasto público federal, que, ao promover a interiorização de equipamentos e serviços públicos especializados, possibilitou àquela cidade exercer a função de polo na oferta de ensino superior público e privado na região.

Ao fazer essa afirmação, enfatiza-se, nessas considerações finais, que, apesar do cenário de manutenção da rigidez fiscal na condução da política macroeconômica no período 2003-2014, foi possível flexibilizar, 
por algum tempo, a execução orçamentária do País, e, de forma mais patente, entre 2006 e 2014, o governo federal removeu temporariamente alguns entraves orçamentários para executar programas estratégicos e ampliar os gastos (despesas e investimentos) em educação superior na região Nordeste, no estado do Rio Grande do Norte e, em particular, na região do Alto Oeste Potiguar, resultando proeminência regional da cidade de Pau dos Ferros.

A região do Alto Oeste Potiguar encontrou, na expansão dos gastos públicos, um elemento de dinamismo econômico-espacial, mediante a concentração, em seu território, de uma estrutura pública de equipamentos e serviços cujos efeitos regionais foram ponderáveis, gerando benefícios coletivos que fortaleceram a centralidade da cidade de Pau dos Ferros. Essa cidade emergiu com o status de cidade intermediária, na medida em que incrementou a oferta de serviços coletivos (públicos/privados) e contribuiu para revigorar e ampliar seus vínculos urbano-regionais, interiorizando a rede urbana no semiárido nordestino e promovendo, assim, maior integração urbano-regional e redefinindo a hierarquia urbana na região.

Mesmo que a descentralização e a interiorização das políticas públicas federais, seja na área de saúde ou na educação superior, tenham produzido repercussões positivas para toda a região Nordeste, notadamente para o semiárido, é importante ressaltar que a capacidade intermediadora da cidade de Pau dos Ferros se deveu, como visto nas seções anteriores, a uma combinação de fatores históricos e conjunturais que assentaram uma estrutura prévia de serviços ofertados, compatível com seu elevado grau de urbanização e complementada por uma localização geográfica favorável, fazendo com que que tais políticas tivessem efeitos multiescalares apreciáveis. Nesse sentido, pode-se afirmar que em determinadas cidades do interior do País, como Pau dos Ferros, a expansão do atendimento à educação superior constituiu, indubitavelmente, um fator de integração urbano-regional.

As funções desempenhadas pela cidade de Pau dos Ferros ampliaram-se e se fortaleceram. Ocorreram a especialização dos serviços de saúde de média complexidade e a constituição de um polo avançado de ensino superior. Isto elevou o nível de relações e articulações interurbanas numa área de influência de maior abrangência e fortaleceu sua função de lugar central ao gerar emprego e renda urbanos e ocupações especializadas. Dessa maneira, tornou mais densas as relações espaciais horizontais na região do Alto Oeste Potiguar e ajudou a intensificá-las, principalmente, em função dos efeitos econômico-urbanos promovidos pela educação superior, elemento decisivo nessa articulação regional.

Conclui-se, portanto, pela relevância que o gasto público pode ter, por meio da expansão e do provimento de equipamentos e serviços públicos especializados, em regiões interiorizadas do País e de menor desenvolvimento urbano-regional, mostrando a potencialidade de um projeto nacional de desenvolvimento regional que compreenda melhor o papel singular das cidades intermediárias na rede urbana, pois, caso contrário, muitas cidades de pequeno ou médio porte do semiárido nordestino continuariam a ser elementos dispersos, débeis e desconexos em relação às hierarquias urbanas mais verticalizadas e concentradas. 


\section{[I] https://orcid.org/0000-0001-9202-4269}

Universidade do Estado do Rio Grande do Norte, Faculdade de Ciências Econômicas, Departamento de Economia. Campus Avançado de Pau dos Ferros. Pau dos Ferros, RN/Brasil.

roniesouza@yahoo.com.br

\section{[II] https://orcid.org/0000-0001-5658-2909}

Universidade Estadual de Campinas, Instituto de Economia, Programa de Pós-Graduação em Desenvolvimento Econômico. Campinas, SP/Brasil.

humbmn@unicamp.br

\section{Notas}

(1) Segundo Orair (2016b, p. 17), o subperíodo 2006-2010 "reflete não somente a flexibilização da política fiscal, que removeu temporariamente entraves orçamentários", mas também a retomada da ação do governo federal "na formulação de programas estratégicos e na retomada de grandes projetos de investimentos".

(2) Delgado e Cardoso Júnior (2001) mostraram a importância da previdência na composição da renda e na sustentação das estratégias de sobrevivência das famílias rurais do Nordeste. Valadares e Galiza (2016) discutem os impactos negativos que uma reforma previdenciária traria ao reduzir o bem-estar e a permanência das famílias no campo, afetando as economias das pequenas cidades.

(3) Ver Guimarães (2010) e Araújo (2013) sobre os efeitos regionais implícitos dessas políticas.

(4) Em 1982, concluiu-se a construção do Açude de Pau dos Ferros com capacidade de 55 milhões de $\mathrm{m}^{3}$ de água.

(5) A Universidade Estadual do Rio Grande do Norte (UERN) foi criada pela lei estadual n. 5.546, com a estadualização da URRN, em 8 de janeiro de 1987.

(6) Seguindo a tendência nacional, a região do Alto Oeste Potiguar foi uma das que mais emanciparam/ criaram municípios, saltando de 12, no Censo de 1960, para 34 municípios, no Censo de 1970.

(7) Ressalte-se o trabalho de Limoeiro (2014), que trata do declínio da desigualdade no Nordeste no período não apenas pelo lado da demanda (transferências intergovernamentais), mas pelo da oferta (investimentos estatais).

(8) Desde Amorim Filho e Serra (2001), passando pelas contribuições de Corrêa (2007) e os trabalhos da Rede de Pesquisadores sobre Cidades Médias (ReCiMe) com Sposito (2007), entre outros.

(9) A elevação de recursos do SUS deu-se basicamente no segundo governo Lula, ou seja, a partir de 2007.

(10) Informações obtidas no site <http://cnes.datasus.gov.br>. 
(11) Para estabelecer a área de influência de Pau dos Ferros, Dantas (2014, p. 190) considerou os seguintes aspectos: “1) os dados de relacionamentos do Regic (IBGE, 2008); 2) os dados de origem residencial dos alunos matriculados nos cursos de graduação do Cameam-UERN (20102012); e 3) os municípios localizados num raio de $100 \mathrm{~km}$ formado a partir da sede do município de Pau dos Ferros".

(12) No ano de 2003, estava à frente da direção do campus a professora Maura Cavalcante Moraes de Sá, responsável pela formação do grupo de trabalho para ampliação da oferta de cursos de graduação no campus da UERN em Pau dos Ferros.

(13) Dados coletados em outubro de 2018.

(14) A secretaria do campus da UERN não dispunha de dados dos alunos do Dinter (UERN/UFPE).

(15) No estado do Rio Grande do Norte, a interiorização dos Institutos Federais passou a ocorrer com o "Plano de Expansão da Rede Federal de Educação Profissional, Científica e Tecnológica", do Ministério da Educação (MEC), de 2005, quando foram implantados os campi de Currais Novos e Ipanguaçu. Dentro da II Fase de expansão, iniciada em 2007, estavam previstos mais seis campi no interior do estado do RN, nas cidades de João Câmara, Santa Cruz, Caicó, Macau, Apodi e Pau dos Ferros.

(16) Dentro da política de interiorização da educação superior pública federal no Estado do Rio Grande do Norte, foi pleiteada, junto ao Ministério da Educação (MEC), a implantação do campus em Pau dos Ferros, sendo criado em 18 de abril de 2012.

(17) Os cursos funcionam na modalidade semipresencial, e todos os cursos de graduação têm 4 anos de duração; os cursos tecnólogos têm 2 anos de duração (informação obtida junto à secretaria do polo em Pau dos Ferros). Outras informações, no site: http://www.anhanguera.com. Acesso em: jul 2018.

(18) Os mantenedores do Curso e Colégio Evolução, no ano de 2006, solicitaram, ao Ministério da Educação, a autorização para se tornarem um Instituição de Ensino Superior - IES, de caráter privado, observando a oportunidade surgida para tal iniciativa na região. A empresa mantém adesão ao Prouni, ao Fies, e ao Programa de Financiamento Pravaler. Informações disponíveis em: http://www.eduevolucao.com.br. Acesso em: jul 2018.

\section{Referências}

AMORIM FILHO, O. B; SERRA, R. V. (2001). "Evolução e perspectivas do papel das cidades médias no planejamento urbano e regional". In: ANDRADE, T. A.; SERRA, R. V. (orgs.). Cidades Médias Brasileiras. Rio de Janeiro, Ipea.

ARAÚJO, T. B. (2013). "Tendências do desenvolvimento regional recente no Brasil". In: BRANDÃO, C. A; SIQUEIRA, H. (orgs.). Pacto federativo, integração nacional e desenvolvimento regional. São Paulo, Perseu Abramo.

BRANDÃO, C. (2017). “Cidades médias como provedoras de bens e serviços públicos e coletivos e como construtoras de cidadania e direitos". In: SILVA, W. R. e SPOSITO, M. E. B. (orgs.). Perspectivas da urbanização: reestruturação urbana e das cidades. Rio de Janeiro, Consequência. 
CORRÊA, R. L. (2007). “Construindo o Conceito de Cidade Média”. In: SPOSITO, M. E. B. (org.). Cidades médias: espaços em transição. São Paulo, Expressão Popular.

(2017). “Cidades médias e rede urbana”. In: SILVA, W. R.; SPOSITO, M. E. B. (orgs.). Perspectivas da urbanização: reestruturação urbana e das cidades. Rio de Janeiro, Consequência.

DANTAS, J. R. Q. (2014). As cidades médias no desenvolvimento regional: um estudo sobre Pau dos Ferros (RN). Tese de doutorado. Natal, Universidade Federal do Rio Grande do Norte.

DANTAS, J. R. Q.; CLEMENTINO, M. L. M.; FRANÇA, R. S. (2015). A cidade média interiorizada: Pau dos Ferros no desenvolvimento regional. Revista Tecnologia e Sociedade. Curitiba, v. 11, n. 23, pp. 129-148.

DELGADO, G.; CARDOSO JÚNIOR, J. C. (2001). A universalização dos direitos sociais no Brasil: a previdência rural nos anos 90: transformações da agricultura e políticas públicas. Brasília, Ipea.

DINIZ, C. C. (2013). Dinâmica regional e ordenamento do território brasileiro: desafios e oportunidades. Texto para discussão, n. 471. Belo Horizonte, UFMG/Cedeplar.

ESTEBAN, A.; LÓPEZ, A. (1989). El papel de las ciudades medias en España. Presente y futuro. UrbanismoCOAM - Revista Oficial del Colegio de Arquitectos de Madrid. Madri, n. 6, pp. 6-16.

GOMES JÚNIOR, E. (2015). Fronteira e reestruturação produtiva na Amazônia brasileira (2003-2013): um estudo sobre a mudança na hierarquia urbana do município de Araguaína (TO) na Amazônia oriental. Dissertação de mestrado. Campinas, Universidade Estadual de Campinas.

GUIMARÃES, L. (2010). "Antecedentes e evolução do planejamento territorial no Brasil”. In: FAVARETO, A. (org.). Políticas de desenvolvimento territorial rural no Brasil, Avanços e desafios. Série Desenvolvimento Rural Sustentável, v. 12. Brasília, IICA.

IBGE - Instituto Brasileiro de Geografia e Estatística (2008). Região de Influência das Cidades 2007. Disponível em: http://www.mma.gov.br/estruturas/PZEE/_arquivos/regic_28.pdf. Acesso em: 2 nov 2017.

(2010). Censo Demográfico de 2010. Rio de Janeiro, IBGE.

(2017a). Censo Demográfico 2000. Disponível em: http://www2.sidra.ibge.gov.br/cd/ defaultcd2000.asp?o=22\&i=P. Acesso em: 12 jan 2017.

(2017b). Divisão Regional do Brasil em Regiões Geográficas Imediatas e Regiões Geográficas Intermediárias 2017. Disponível em: https://biblioteca.ibge.gov.br/visualizacao/livros/liv100600. pdf. Acesso em: 6 jun 2018.

(2018). Produto Interno Bruto dos municípios, 2002-2015. IBGE. Disponível em: https://sidra. ibge.gov.br/pesquisa/pib-munic/tabelas. Acesso em: 10 fev 2018.

(2020). Censo Demográfico de 2010. Rio de Janeiro, IBGE.

IFRN-SIGAA (2018). Sistema Integrado de Gestão de Atividades Acadêmicas. (Dados fornecidos pela secretaria da unidade local). Pau dos Ferros, nov.

LIMOEIRO, D. (2014). Além das transferências de renda: o declínio da desigualdade regional no Brasil na década de 2000. Brasília, Editora UNB.

LUCENA, R. L.; CABRAL JÚNIOR, J. B.; STEINKE, E. T. (2018). Comportamento Hidroclimatológico do Estado do Rio Grande do Norte e do Município de Caicó. Revista Brasileira de Meteorologia. São Paulo, v. 33, n. 3, pp. 485-496. 
MAIA GOMES, G. (2001). Velhas secas em novos sertões: continuidade e mudanças na economia do Semi-Árido e dos Cerrados nordestinos. Brasília, Ipea.

MTE - Ministério da Economia/Secretaria do Trabalho (2016). Relação Anual de Informações Sociais (Rais). Disponível em: http://bi.mte.gov.br/bgcaged/inicial.php. Acesso em: 4 nov 2017.

ORAIR, R. O. (2016a). Investimento público no Brasil: trajetória e relações com o regime fiscal. Texto para Discussão, n. 2215. Rio de Janeiro, Ipea.

(2016b). "Dilemas do financiamento das políticas públicas nos municípios brasileiros: uma visão geral". In: COSTA, M. A. (2016). O Estatuto da Cidade e a Habitat III: um balanço de quinze anos da política urbana no Brasil e a nova agenda urbana. Brasília, Ipea.

PORTO, L. R. (2016). Urbanização e dinâmica econômica na rede urbana do estado da Bahia (19402010): o caso de Vitória da Conquista (BA). Dissertação de mestrado. Campinas, Universidade Estadual de Campinas.

SILVA, F. B. S. et al. (2013) A dinâmica urbana de Pau dos Ferros sob a ótica da expansão urbana e imobiliária: fenômeno, motivo e consequências. Relatório Final de Pesquisa. Natal, UERN.

SIMÕES, R.; AMARAL, P. V. (2011). Interiorização e Novas Centralidades Urbanas: uma visão prospectiva para o Brasil. Revista Economia. Brasília, v. 12, n. 3, pp. 553-579.

SOUZA, R. C. de et al. (2014). A construção civil na cidade de Pau dos Ferros/RN: emprego, renda e qualificação. Relatório Final de Pesquisa. Natal, UERN.

SPOSITO, M. E. B. (2007). "Sobre novas possibilidades e perspectivas: historiando o nosso percurso e apresentando nossos textos sobre cidades médias (Prefácio)". In: SPOSITO, M. E. B. (org). Cidades médias: espaços em transição. São Paulo, Expressão Popular.

UERN - PAU DOS FERROS (2016). 40 anos transformando vidas. Campus de Pau dos Ferros. Pau dos Ferros-RN.

UERN-SIGAA (2018). Sistema Integrado de Gestão de Atividades Acadêmicas. (Dados fornecidos pela secretaria da unidade local). Pau dos Ferros, out.

UFERSA-SIGAA (2018). Sistema Integrado de Gestão de Atividades Acadêmicas. (Dados fornecidos pela secretaria da unidade local). Pau dos Ferros, nov.

VALADARES A. A.; GALIZA M. (2016). Previdência rural: contextualizando o debate em torno do financiamento e das regras de acesso. Nota técnica, n. 25. Brasília, Ipea.

VIEIRA, D. J. (2017). "Evolução do ensino superior brasileiro em período recente: novas perspectivas para o desenvolvimento regional?". In: MONTEIRO NETO, A. et al. Desenvolvimento regional no Brasil: políticas, estratégias e perspectivas. Rio de Janeiro, Ipea.

Texto recebido em 5/maio/2020

Texto aprovado em 10/ago/2020 